\title{
Clinicopathological Study of Mucinous Carcinoma of Breast with Emphasis on Cytological Features: A Study at Tertiary Care Teaching Hospital of South India
}

\author{
Panduranga Chikkannaiah ${ }^{1}$ Deinu Thangngeo ${ }^{1} \quad$ Chanigaramaiah Guruprasad $^{1}$ \\ Srinivasamurthy Venkataramanappa ${ }^{1}$
}

1Department of Pathology, Employees' State Insurance Corporation

Address for correspondence Panduranga Chikkannaiah, Department of Pathology, Employees' State Insurance Corporation Medical College and PGIMSR, Bengaluru 560010, Karnataka, India (e-mail: pandupath@gmail.com).

J Lab Physicians:2020;12:68-75

\begin{abstract}
Introduction Mucinous carcinoma (MC) is a rare form of breast cancer. It accounts for 1 to $7 \%$ of the cases and characterized by the presence of extracellular mucin (ECM). Depending on the amount of mucin, it is classified into pure mucinous carcinoma (>90\%, PMC) and mixed mucinous carcinoma (MMC; <90\%). In comparison to most common subtypes, $\mathrm{MC}$ is having better prognosis. There exist clinicopathological differences among PMC and MMC and also MC and IDC-NOS.

Materials and Methods MCs diagnosed between January 2012 and December 2017 were included. Fine needle aspiration cytology smears were screened for cellularity, ECM, nuclear pleomorphism, signet ring cells (SRC), mucinophages, and myxovascular fragments (MVF). Histopathology slides were screened to confirm the diagnosis. Immunohistochemistry slides were graded as per the standard protocol. Statistical analyses were performed by SPSS software.

Results In the present study, MC constituted 3.3\%. The mean age of the patients

Keywords

- breast carcinoma

- mucinous carcinoma

- FNAC

- extracellular mucin

- mucinophages

- signet ring cells

- myxovascular

fragments was 50.9 years. ECM, mucinophages, and SRC were the key diagnostic cytological features. The PMC and MMC were clinicopathologically distinct with respect to gross findings and lymph node status. MMCs were highly proliferative. The mean duration of follow-up was 24.5 months. Complications were more common in MMC than PMC. Lymph node involvement is the key prognostic factor and it is independent of other prognostic factors like age, size, and hormonal receptor status.

Conclusion PMC are rare subtype of breast cancer. The diagnostic cytological features are ECM, MVF, and SRC. MMC and PMC are clinicopathologically and genetically distinct.
\end{abstract}

\section{Introduction}

The incidence of breast cancer is increasing globally. It is the leading cause of cancer death among females in India. The age adjusted incidence is 25.8 per $1,00,000$ population. Invasive carcinoma not otherwise specified (IDC-NOS) and lobular carcinoma are the most common histological subtypes. Mucinous carcinoma (MC) is an uncommon histological subtype and accounts for 1 to $7 \%$ of all breast carcinomas. It is 
characterized by the presence of extracellular mucin (ECM) material. In comparison to most common subtypes, MC has better prognosis. Depending on the amount of ECM, MC is classified into pure mucinous carcinoma (PMC) and mixed mucinous carcinomas (MMC). PMC has mucinous component of $>90 \%$, usually confined to stage I and II, positive for hormonal receptors and less chance of metastasis in comparison to IDC. ${ }^{1-4}$

MMC has mucinous component less than $90 \%$, in addition they have solid component composed of IDC, lobular or neuroendocrine. Due to the distinct clinicopathological parameters their exists prognostic difference between PMC and MMC. ${ }^{1-4}$

Even though fine needle aspiration cytology (FNAC) is well accepted as initial diagnostic modality for breast cancer, ${ }^{5}$ the cytological features of PMC are less defined. Cytological diagnosis of PMC is challenging as the features overlap with many benign and malignant lesions. ${ }^{6,7}$

Hence, this study was undertaken to document the cytological features of PMC and MMC and to study the clinicopathological parameters associated with PMC and MMC.

\section{Aims and Objectives}

1. To study and compare the cytological features of pure and MMC of breast.

2. To study and compare the clinicopathological parameters associated with pure and MMC.

\section{Material and Methods}

This is a retrospective study conducted in the Department of Pathology at a tertiary care medical college and teaching hospital of South India. The study period was from January 2012 to December 2017 (6 years). All the cases which have been diagnosed as MC on histopathology were included. Patients demographic details like age, sex, and clinical findings were retrieved from the clinical case sheets. Histopathology slides and corresponding FNAC slides were removed from the archives. If the histopathology slides were not available, paraffin blocks were removed; 5-mm sections were cut and stained by Hematoxylin and Eosin (H\&E). Even the corresponding immunohistochemistry slides were retrieved. Pathological findings like laterality of the breast, quadrant involved, presence of nipple retraction/discharge, side of the tumor were noted from the pathology files. The FNAC smears were screened by three pathologists and findings like cellularity, presence of ECM, pleomorphism of nuclei; signet ring cells (SRC), mucinophages, and myxovascular fragments (MVFs) were recorded. The histopathology slides were also re-screened to confirm the diagnosis. Findings like laterality of the breast, quadrant, presence or absence of lymphovascular invasion, perineural invasion, associated changes in the surrounding breast parenchyma, lymph node status, and stage of the tumor were noted. Immunohistochemistry slides for estrogen receptor (ER), progesterone receptor (PR), human epidermal growth factor receptor 2 (HER $2 \mathrm{Neu}$ ) and
$\mathrm{K}_{\mathrm{i}}-67$ were re-screened, and the Allred score was used to measure ER and PR positivity. HER 2 Neu was graded from 0 to 3. A score of 2+ on IHC (ImmunoHistoChemistry) or FISH (Fluorescence In Situ Hybridization) was taken as positive. Ki-67 grading was done, $>14 \%$ positivity was considered as proliferative. The results were tabulated. The patients were followed up; follow-up is the interval between the date of operation to the date of most recently identified patient contact. Complications if any were recorded. The cases were categorized as PMC if the amount of mucin was more than 90\% and MMC if amount of mucin was $<90 \%$ with adjacent areas of ductal component/lobular carcinoma/neuroendocrine carcinoma. The clinicopathological findings were compared between the two groups. The MC cases were also classified into lymph node positive and negative cases and prognostic parameters like age, sex, and hormonal receptor status were compared between the two groups.

Statistical analysis was performed using Statistical Package for Social Sciences (SPSS) for Windows version 22.0 Released 2013 (IBM Corp.). Descriptive analysis includes expression of study parameters in terms of mean and standard deviation for continuous variables, whereas in terms of frequency and proportions, categorical Chi-square test/Fischer Exact test was used to compare the distribution of study variables between pure and mixed mucinous groups. Independent Student $t$-test was used to compare the mean age between two groups. The level of significance was set at $p<0.05$.

\section{Results}

During the study period, a total of 420 cases of breast carcinomas were studied, out of which 14 cases were MCs, constituting $3.3 \%$ of all the cases. All were female patients. The age of the patients ranged from 34 to 70 years with mean age of 50.9 years. The tumors were equally distributed among both breasts. All the cases were presented with lump in the breast; in addition, one case had nipple discharge. MCs were observed in younger age group. Not much age group difference was observed between two groups. The mean age of patient in PMC was $52.1 \pm 13.5$ years while among MMC were $49.6 \pm 11.2$ years ( - Table $\mathbf{1}$ ).

The key cytological features observed in the study were cellularity, pleomorphism of nuclei, ECM, SRCs, and mucinophages, and MVFs. ECM is the free mucin present outside the cell. SRCs are tumor cells having eccentrically placed nuclei and vacuolated cytoplasm due to intracellular mucin. Mucinophages are the histiocytes which have engulfed the ECM and having central to eccentrically placed nuclei with vacuolated cytoplasm. MVFs are branching vessels along with tumor cells and mucin material.

MCs are known for low cellularity on cytology, five (71.4\%) cases of PMC were paucicellular ( $\boldsymbol{- F i g}$. 1a-c), while six cases (85.7\%) of MMC were having mild to moderate cellularity $(\sim$ Fig. 1g-i $)(p=0.10)$. The cells in MC were bland and benign looking without much pleomorphism; all the seven cases in PMC and five cases in MMC exhibited mild pleomorphism ( $p=$ 0.32). ECM and mucinophages ( - Fig. 1; day e) were observed in seven (100\%) cases of PMC, while one of the cases of MMC 
Table 1 Clinicopathological differences between pure and mixed mucinous carcinoma

\begin{tabular}{|c|c|c|c|c|}
\hline Parameters & Categories & $\begin{array}{l}\text { Pure mucinous } \\
\text { carcinoma (7) }\end{array}$ & $\begin{array}{l}\text { Mixed mucinous } \\
\text { carcinoma (7) }\end{array}$ & $p$-Value \\
\hline \multirow[t]{8}{*}{ Age (mean and SD) } & \multirow[t]{8}{*}{ Mean \pm SD } & 62 & 45 & \multirow[t]{8}{*}{$0.70^{\mathrm{a}}$} \\
\hline & & 38 & 35 & \\
\hline & & 53 & 41 & \\
\hline & & 65 & 55 & \\
\hline & & 45 & 51 & \\
\hline & & 34 & 50 & \\
\hline & & 68 & 70 & \\
\hline & & $52.1 \pm 13.5$ & $49.6 \pm 11.2$ & \\
\hline \multirow{8}{*}{$\begin{array}{l}\text { Tumor size in cm } \\
\text { (mean) }\end{array}$} & \multirow[t]{8}{*}{ Mean \pm SD } & 4.5 & 5 & \multirow[t]{8}{*}{0.68} \\
\hline & & 1.5 & 3 & \\
\hline & & 6.5 & 3 & \\
\hline & & 2 & 4 & \\
\hline & & 4.5 & 6 & \\
\hline & & 7 & 4 & \\
\hline & & 1.5 & 5.5 & \\
\hline & & $3.9 \pm 2.3$ & $4.3 \pm 1.18$ & \\
\hline \multirow[t]{2}{*}{ Quadrant } & Upper outer & $1(14.3)$ & $3(42.9)$ & \multirow[t]{2}{*}{$0.56^{\mathrm{b}}$} \\
\hline & Central & $6(85.7)$ & $2(28.6)$ & \\
\hline \multirow[t]{2}{*}{ Gross } & Mucinous areas & $7(100)$ & $1(14.3)$ & \multirow[t]{2}{*}{$0.004^{b, c}$} \\
\hline & Solid areas & $0(0)$ & $6(85.7)$ & \\
\hline \multirow[t]{2}{*}{ Lymph node status } & Negative & $6(85.7)$ & $2(28.6)$ & \multirow[t]{2}{*}{$0.03^{b, c}$} \\
\hline & Positive & $1(14.3)$ & $5(71.4)$ & \\
\hline \multirow[t]{4}{*}{ Stage } & 1 & $2(28.6)$ & $0(0.0)$ & \multirow[t]{4}{*}{$0.39^{d}$} \\
\hline & II & $4(57.1)$ & $4(57.1)$ & \\
\hline & III & $1(14.3)$ & $3(42.9)$ & \\
\hline & IV & $0(0.0)$ & $0(0.0)$ & \\
\hline \multirow[t]{2}{*}{ ER } & Negative & $1(14.3)$ & $1(14.3)$ & \multirow[t]{2}{*}{$1.00^{\mathrm{b}}$} \\
\hline & Positive & $6(85.7)$ & $6(85.7)$ & \\
\hline \multirow[t]{2}{*}{$\mathrm{PR}$} & Negative & $2(28.6)$ & $1(14.3)$ & \multirow[t]{2}{*}{$1.00^{\mathrm{b}}$} \\
\hline & Positive & $5(71.4)$ & $6(85.7)$ & \\
\hline \multirow[t]{2}{*}{ Her 2 New } & Negative & $5(71.4)$ & $3(42.9)$ & \multirow[t]{2}{*}{$0.59^{d}$} \\
\hline & Positive & $2(28.6)$ & $4(57.1)$ & \\
\hline \multirow[t]{2}{*}{$\mathrm{K}_{\mathrm{i}} 67$} & Negative & $6(85.7)$ & $2(28.6)$ & \multirow[t]{2}{*}{$0.03^{b, c}$} \\
\hline & Positive (> 14\%) & $1(14.3)$ & $5(71.4)$ & \\
\hline \multirow[t]{2}{*}{ Complications } & Present & $1(14.3)$ & $5(71.4)$ & \multirow[t]{2}{*}{$0.03^{b, c}$} \\
\hline & Absent & $6(85.7)$ & $2(28.6)$ & \\
\hline
\end{tabular}

Abbreviations: ER, estrogen receptor; PR, progesterone receptor; SD, standard deviation.

Note: The numbers in the parenthesis denote the percentage.

had mucin and mucinophages $(14.3 \% ; p=0.004)$. SRCs were observed in seven (100\%) cases of PMC and two (28.6\%) cases of MMC $(p=0.02)$. MVFs were observed in five cases $(71.4 \%)$ of PMC and one (14.3\%) case of MMC (-Fig. 1f). Among the cytological parameters, presence of ECM, SRC, and mucinophages was diagnostic of PMC and was statistically significant with a $p$-value of $<0.05$ ( - Table 2 ).

All the cases had undergone modified radical mastectomy with axillary clearance. Six $(85.7 \%)$ cases of PMC were located in central quadrant and five (71.4\%) cases of MMC were located in upper outer quadrant $(p=0.56)$. PMCs were circumscribed soft tumor with cystic and prominent mucoid areas which was observed in all the cases (100\%; - Fig. 2a) while MMCs were poorly circumscribed solid gray white tumor with mucoid change.

PMCs were microscopically characterized by abundant mucinous areas with bland tumor cells floating within them ( Fig. 2b-d), while MMCs were having mucinous areas as 

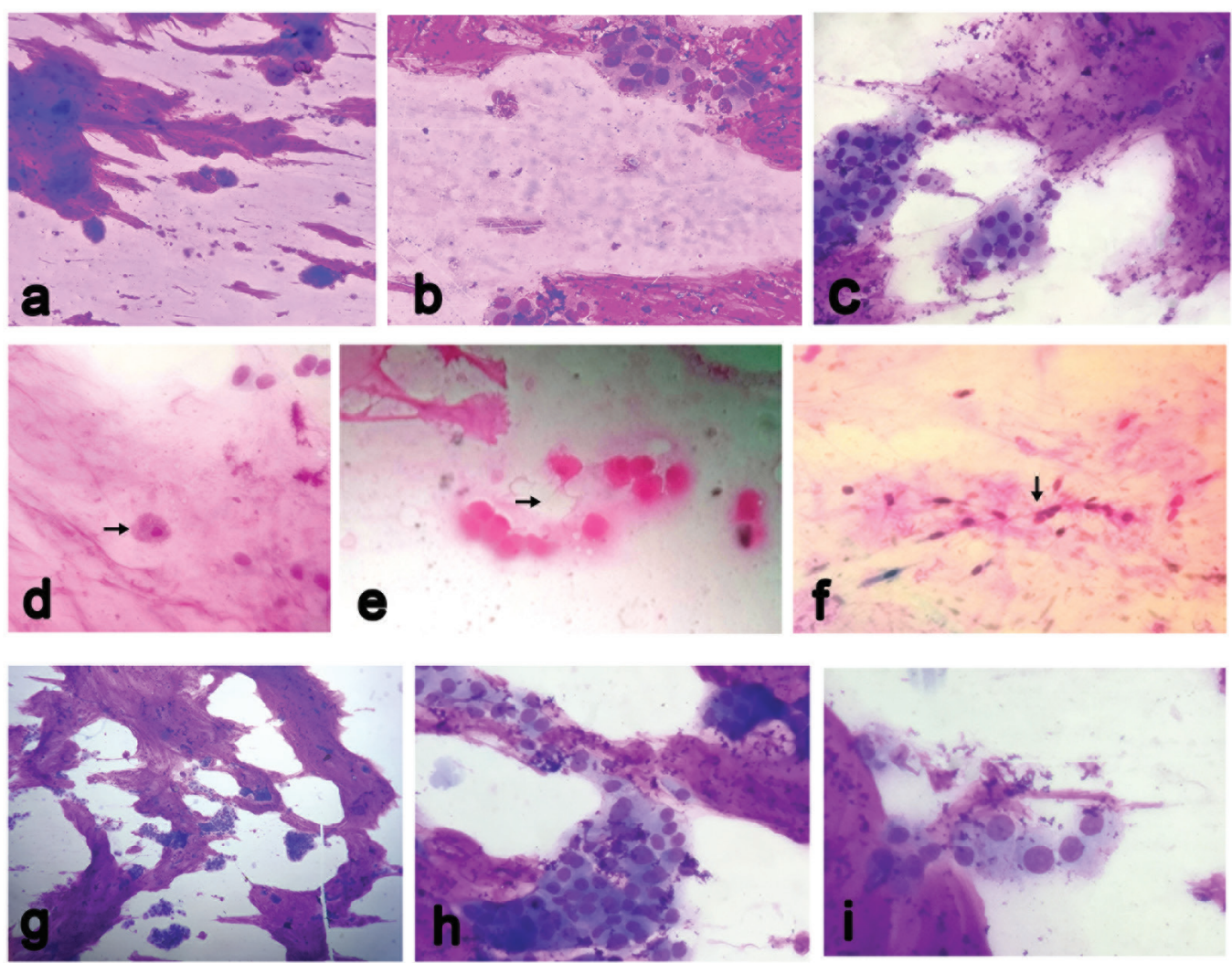

Fig. 1 (a) Microphotograph of cytological smear from a case of pure mucinous carcinoma, showing abundant extracellular mucin with clusters of floating tumor cells which are bland (Leishman, 10×); (b,c) Higher magnification of the same (Leishman, 40×). (d,e) Microphotograph showing mucinophages (black arrow) (Leishman, 40×); (f) Microphotograph showing myxovascular fragments (black arrow) (Leishman, 40×). (g) Microphotograph of cytological smear from a case of mixed mucinous carcinoma, showing extracellular mucin, high cellularity with mild pleomorphic nuclei. (Leishman,10×); (h,i) Higher magnification of the same (Leishman, 40×).

Table 2 Cytological findings and differences between pure and mixed mucinous carcinoma

\begin{tabular}{|c|c|c|c|c|}
\hline Parameters & Categories & $\begin{array}{l}\text { Pure mucinous } \\
\text { carcinoma (7) }\end{array}$ & $\begin{array}{l}\text { Mixed mucinous } \\
\text { carcinoma (7) }\end{array}$ & $p$-Value \\
\hline \multirow[t]{3}{*}{ Cellularity } & Paucicellular & $5(71.4)$ & $1(14.3)$ & \multirow[t]{3}{*}{$0.10^{\mathrm{a}}$} \\
\hline & Cellular & $2(28.6)$ & $6(85.7)$ & \\
\hline & Absent & $0(0.0)$ & $6(85.7)$ & \\
\hline \multirow[t]{3}{*}{ Pleomorphism of nuclei } & Mild & $7(100.0)$ & $5(71.4)$ & \multirow[t]{3}{*}{$0.32^{b}$} \\
\hline & Moderate & $0(0.0)$ & $2(28.6)$ & \\
\hline & High & $0(0.0)$ & $0(0.0)$ & \\
\hline \multirow[t]{2}{*}{ Mucin } & Present & $7(100.0)$ & $1(14.3)$ & \multirow[t]{2}{*}{$0.004^{a, c}$} \\
\hline & Absent & $0(0.0)$ & $6(85.7)$ & \\
\hline \multirow[t]{2}{*}{ Signet ring cells } & Present & $7(100.0)$ & $2(28.6)$ & \multirow[t]{2}{*}{$0.02^{\mathrm{a}, \mathrm{c}}$} \\
\hline & Absent & $0(0.0)$ & $5(71.4)$ & \\
\hline \multirow[t]{2}{*}{ Mucinophages } & Present & $7(100.0)$ & $1(14.3)$ & \multirow[t]{2}{*}{$0.004^{a, c}$} \\
\hline & Absent & $0(0.0)$ & $6(85.7)$ & \\
\hline \multirow[t]{2}{*}{ Myxovascular fragments } & Present & $5(71.4)$ & $1(14.3)$ & \multirow[t]{2}{*}{$0.10^{\mathrm{a}}$} \\
\hline & Absent & $2(28.6)$ & $6(85.7)$ & \\
\hline
\end{tabular}

Note: The numbers in the parenthesis denote the percentages.

aFischer Exact test.

${ }^{\mathrm{b} C h i}$-square test

'Statistically significant.

Independent student $t$-test. 
72 Clinicopathological Study of Mucinous Carcinoma of the Breast Chikkannaiah et al.
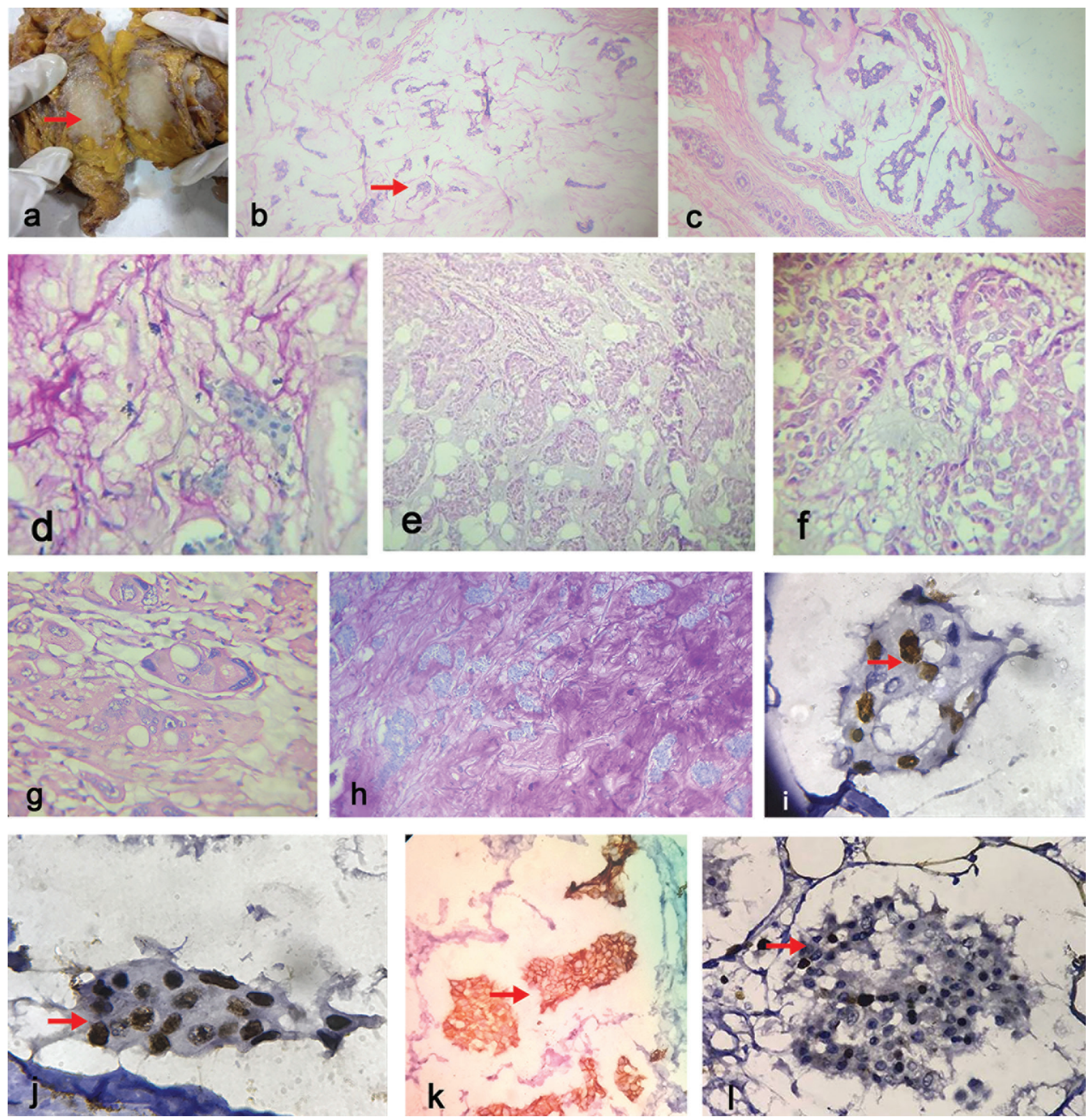

Fig. 2 (a) Gross specimen of breast showing infiltrative gray white tumor with mucinous areas (red arrow). (b) Microphotograph of pure mucinous carcinoma showing abundant extracellular mucin with clusters of floating tumor cells which are bland (red arrow) (Hematoxylin and Eosin [H\&E] 10×); (c) Same case showing surrounding fibrocystic areas (H\&E, 10×); (d) Periodic stain highlighting the mucinous areas (Periodic acid-Schiff stain [PAS] 40×). (e) Microphotograph of mixed mucinous carcinoma showing alternate areas of extracellular mucin and tumor cells clusters. Note the pleomorphic nuclei of tumor cells (H\&E, 10×). (f,g) Higher magnification of the same (H\&E, 40×). (h) Periodic stain highlighting the mucinous areas (PAS, 40×). Immunohistochemistry showing nuclear positivity for estrogen receptor (i ER, 40×), progesterone receptor (j, PR, 40×). Membrane positivity for Her 2 New (k, Her 2 new, 40×). Increased proliferative marker (I, $\left.\mathrm{K}_{\mathrm{i}} 67,40 \times\right)$.

described above along with solid areas showing invasive ductal component by the side of the mucinous areas ( $\mathbf{- F i g . ~ 2 e - h}$ ). In our study, two MMC cases showed intraductal component and one case of PMC showed fibrocystic areas ( - Fig. 2c). One case $(14.3 \%)$ of PMC and five (71.4\%) cases of MMC showed metastasis in the ipsilateral axillary node $(p=0.03)$. None of the cases had distant metastasis at the time of diagnosis. The mucin was positive on Periodic acid-Schiff or (PAS) stain ( - Fig. 2; day h). Four cases of PMC were in stage II, two cases were in stage I, and one case in stage III. Among MMCs four cases were in stage II and three cases were in stage III $(p=0.39)$.

With respect to ER, PR, and HER 2 Neu immunostaining, no difference was observed between PMC and MMC. However, MMCs were having high proliferative index with five cases $\left(71.4 \%\right.$ ) having $K_{i} 67$ index $>14 \%$, while PMCs were having low proliferative tumor with one case having $\mathrm{K}_{\mathrm{i}} 67$ index $>14 \%(p=0.03 ;$ - Fig. 2i-1). 
The initial cytological diagnosis was correlated with histopathological findings; among the seven cases of PMC, four were reported as MC while three cases were reported as ductal carcinoma with mucinous features. Among the MMCs, five were reported as ductal carcinomas and one case each was reported as MC and Phyllodes tumor, respectively (- Table $\mathbf{3}$ ).

All the patients were telephonically contacted. The duration of follow-up ranged from 3 months to 70 months with mean of 24.5 months. All the cases of PMC were treated with chemotherapy. Out of the seven cases, six were symptom free and one case developed lung metastasis. Out of the seven cases of MMC, three were treated with hormonal therapy, all three had complications: one case developed upper limb edema, the other case developed ipsilateral recurrence, and the third case developed cervical lymph node metastasis. Two cases were treated with chemotherapy, on follow-up one case had ipsilateral recurrence, and another was symptom free. One case was treated with radiotherapy + chemotherapy + hormonal therapy; on follow-up patient developed upper limb edema. Another case was treated with chemotherapy and hormonal therapy who was symptom free on follow-up. Complications were more frequently observed with MMC than $\operatorname{PMC}(p=0.03$; - Tables 1 and 4$)$.
In the present study, all the lymph node involved cases had postoperative complications. Those without lymph node were disease free. Hence lymph node involvement was the key prognostic factor. In the present study, the lymph node involvement was independent of other prognostic factors like age, tumor size, and hormonal receptor status (- Table 5).

\section{Discussion}

In the present study, MC constituted 3.3\% of the cases and our findings were in sync with the literature. The prevalence varies across the world and range from 2 to $7 \%$. The reported prevalence in China is $2.4 \%{ }^{4}$ and in Taiwan is 3.4\%. ${ }^{1}$ MC is a disease of post-menopausal women and observed in patients a decade older than IDC in the western countries. In the present study, cases were distributed between 34 and 70 years with four cases occurring after the age of 60 years. MC occurring below the age of 35 years is rare and accounts for $1 \%$ of all breast cancers. ${ }^{1}$ In the present study, there was no age difference between PMC and MMC. The mean age among PMC was $52.1 \pm 13.5$ years and among MMC was $49.6 \pm 11.2$ years and our findings were consistent with the literature. The mean age observed by

Table 3 FNAC and histopathology diagnosis among mucinous carcinoma

\begin{tabular}{|c|c|c|c|c|}
\hline SI no. & FNAC diagnosis & Histopathology & Tumor size & Stage \\
\hline 1 & Ductal carcinoma & MMC & $5 \times 4 \times 2$ & T2 N1M× (IIB) \\
\hline 2 & Mucinous carcinoma & PMC & $4.5 \times 2 \times 2$ & T2 N0M× (IIA) \\
\hline 3 & $\begin{array}{l}\text { Ductal carcinoma with mucinous } \\
\text { features }\end{array}$ & PMC & $1.5 \times 1 \times 1$ & T1 N0M× (I) \\
\hline 4 & Phyllodes tumor & MMC & $3 \times 3 \times 1.5$ & $\mathrm{~T} 2 \mathrm{~N} 0 \mathrm{M} \times(\mathrm{IIA})$ \\
\hline 5 & Mucinous carcinoma & PMC & $2 \times 1.5 \times 0.5$ & $\mathrm{~T} 2 \mathrm{~N} 0 \mathrm{M} \times(\mathrm{IIA})$ \\
\hline 6 & Ductal carcinoma & MMC & $3 \times 2 \times 2$ & $\mathrm{~T} 2 \mathrm{~N} 0 \mathrm{M} \times(\mathrm{IIA})$ \\
\hline 7 & Mucinous carcinoma & PMC & $4.5 \times 4 \times 3.5$ & $\mathrm{~T} 2 \mathrm{~N} 0 \mathrm{M} \times(\mathrm{IIA})$ \\
\hline 8 & Mucinous carcinoma & MMC & $6 \times 5.5 \times 3$ & T4bN3aM× (IIIC) \\
\hline 9 & $\begin{array}{l}\text { Ductal carcinoma with mucinous } \\
\text { features }\end{array}$ & PMC & $7 \times 4 \times 4.5$ & T3N1M× (IIIA) \\
\hline 10 & Ductal carcinoma & MMC & $4 \times 2 \times 2$ & $\mathrm{~T} 2 \mathrm{~N} 2 \mathrm{M} \times(\mathrm{IIIA})$ \\
\hline 11 & Ductal carcinoma with mucinous areas & PMC & $1.5 \times 1 \times 1 \times 1$ & $\mathrm{~T} 1 \mathrm{~N} 0 \mathrm{M} \times(\mathrm{I})$ \\
\hline 12 & Ductal carcinoma with mucinous areas & MMC & $5.5 \times 4 \times 3$ & T4N1M× (IIIB) \\
\hline 13 & Mucinous carcinoma & PMC & $6.5 \times 4.5 \times 4$ & T3N0M $\times(I I B)$ \\
\hline 14 & Ductal carcinoma with mucinous areas & MMC & $4 \times 3 \times 3$ & $\mathrm{~T} 2 \mathrm{~N} 0 \mathrm{M} \times(\mathrm{IIA})$ \\
\hline
\end{tabular}

Abbreviations: FNAC, fine needle aspiration cytology; MMC, mucinous carcinoma; PMC, pure mucinous carcinoma.

Table 4 Mode of treatment and follow-up details of mucinous carcinoma

\begin{tabular}{|l|l|l|l|}
\hline Histological type & No of cases & Mode of treatment & Follow-up complications \\
\hline PMC & 7 & MRM + C & $\begin{array}{l}\text { Lung metastasis (1) } \\
\text { DFS (6) }\end{array}$ \\
\hline \multirow{3}{*}{ MMC } & 3 & MRM + H & $\begin{array}{l}\text { Ipsilateral upper limb edema (1) } \\
\text { Ipsilateral recurrence (1) } \\
\text { Cervical node metastasis (1) }\end{array}$ \\
\cline { 2 - 4 } & 2 & MRM +C & $\begin{array}{l}\text { Ipsilateral recurrence (1) } \\
\text { DFS (1) }\end{array}$ \\
\cline { 2 - 4 } & 1 & MRM+R+C+H & Ipsilateral upper limb edema (1) \\
\hline
\end{tabular}

Abbreviations: C, chemotherapy; DFS, disease-free survive; $\mathrm{H}$, hormonal therapy; MMC, mucinous carcinoma; MRM, modified radical mastectomy; $\mathrm{PMC}$, pure mucinous carcinoma; $\mathrm{R}$, radiotherapy. 
Table 5 Association of prognostic factors age, tumor size, and hormonal receptor status with lymph node involvement

\begin{tabular}{|c|c|c|c|c|}
\hline Parameters & Categories & $\begin{array}{l}\text { Lymph node involvement } \\
\text { positive (6) }\end{array}$ & $\begin{array}{l}\text { Lymph node involvement } \\
\text { negative ( } 8 \text { ) }\end{array}$ & $p$-Value \\
\hline Age (mean $\pm \mathrm{SD}$ ) & Mean \pm SD & $\begin{array}{l}45 \\
51 \\
34 \\
50 \\
35 \\
70 \\
47.5 \pm 13.18\end{array}$ & $\begin{array}{l}62 \\
38 \\
53 \\
65 \\
41 \\
45 \\
55 \\
68 \\
53.37 \pm 11.2\end{array}$ & 0.3858 \\
\hline $\begin{array}{l}\text { Tumor size in cm } \\
\text { (mean) }\end{array}$ & Mean \pm SD & $\begin{array}{l}5 \\
3 \\
6 \\
7 \\
4 \\
5.5 \\
5.5 \pm 1.42\end{array}$ & $\begin{array}{l}4.5 \\
1.5 \\
6.5 \\
2 \\
3 \\
4 \\
4 \\
1.5 \\
3.3 \pm 1.72\end{array}$ & 0.073 \\
\hline \multirow[t]{2}{*}{ ER } & Negative & $1(16.6)$ & $1(12.5)$ & \multirow[t]{2}{*}{$1.00^{\mathrm{a}}$} \\
\hline & Positive & $5(83.3)$ & 7 (87.5) & \\
\hline \multirow[t]{2}{*}{ PR } & Negative & $1(16.6)$ & $1(12.5)$ & \multirow[t]{2}{*}{$1.00^{\mathrm{a}}$} \\
\hline & Positive & $5(83.3)$ & $7(87.5)$ & \\
\hline \multirow[t]{2}{*}{ HER-2 Neu } & Negative & $2(33.3)$ & $4(50.0)$ & \multirow[t]{2}{*}{$0.627^{\mathrm{a}}$} \\
\hline & Positive & $4(66.6)$ & $4(50.0)$ & \\
\hline
\end{tabular}

Abbreviations: ER, estrogen receptor; HER-2 Neu, human epidermal growth factor receptor 2; PR, progesterone receptor; SD, standard deviation.

Tseng et $\mathrm{al}^{1}$ was 49.8 years, Bae et $\mathrm{al}^{2}$ was 44 years, Jayaram et $\mathrm{al}^{6}$ was 52 years, and Lei et $\mathrm{al}^{4}$ was 52.26 years. The occurrence of MC in younger age may be due to genetic and environmental changes, increased awareness toward the disease in general public, availability of reliable diagnostic methods, and breast of Asian women being small and dense. ${ }^{1}$

Cytological diagnosis of $\mathrm{MC}$ is challenging. From the observation of our study and on review of the literature, the key cytological features of PMC were mucinophages, SRC, and MVF with paucicellular, bland looking cells in the background of mucinous material. In contrast, MMC will have tumor cells with mild to moderate pleomorphism with cells in sheets and clusters. SRC, mucinophages, and MVF were rarely observed. ${ }^{5-7}$

Review of the literature revealed majority of the published literature pertaining to the cytological diagnosis MC are single case reports with only few series available. ${ }^{6-10}$ Adhikari et $\mathrm{al}^{7}$ studied eight cases of MC (5 PMC + 3 MMC) and observed presence of ECM along with single and cluster of tumor cells floating in them and thin walled capillaries as prominent features in five cases of PMC. Three cases of MMC showed in addition to mucin, pleomorphic clusters of tumor cells (as observed in our study). Jayaram et al ${ }^{6}$ in their study on 27 cases of MC observed ECM, MVF, hypocellularity, SRCs, and psammoma bodies as the prime cytological features. They did not subcategorize them.

Haji et al ${ }^{11}$ in their study on cytological features of four special types of breast cancer (mucinous, medullary, apocrine, and papillary cancer) documented that SRC (62.5\%) and back ground mucin (87.5\%) were consistently found in MC compared with other special types. Lymph mononuclear cell infiltration was specific for medullary carcinoma. Apocrine cells and papillary clusters were specific for apocrine carcinomas and papillary carcinomas, respectively. They also observed that the classical finding described in special type of breast carcinoma is not observed in invasive ductal carcinoma not otherwise specified.

Fibroadenoma (FA), phyllodes tumor (PT) with mucinous differentiation, and mucocele are the common cytological differential diagnosis for MC. In FA and PT, the ductal cells are smaller in size; they are arranged in cohesive clusters and in staghorn pattern with good number of bipolar bare nuclei and stromal fragments in the background. Mucocele will have abundant ECM along with clusters of ductal epithelial cells rather than present in singles. ${ }^{6}$

In the present study, MMCs were slightly more in size than PMCs ( $4.3 \pm 1.18$ vs. $3.9 \pm 2.3 \mathrm{~cm} ; p=0.68)$ and our findings are in sync with Lei et al. ${ }^{4} \mathrm{Few}$ authors documented that MC which is less than $5 \mathrm{~cm}$ will have good prognosis. ${ }^{6}$ Tseng et $\mathrm{al}^{1}$ and Bae et $\mathrm{al}^{2}$ in their study observed no difference with respect to size among MC and IDC.

Morphologically, PMCs are characterized by the presence of mucin in $>90 \%$ of tumors. MMCs are characterized by solid components. In most of the cases, solid component resembles IDC-NOS (as observed in our case). In some cases, it may show lobular component having smaller tumor cells arranged in singles and on IHC shows loss of E-cadherin. In neuroendocrine differentiation, the tumor cells have abundant granular cytoplasm which will be positive for synaptophysin, neuron-specific enolase, and chromogranin. ${ }^{3}$ 
PMCs have distinct clinicopathological parameters compared with other types of breast carcinoma not only morphologically but also genetically. ${ }^{1-4}$ In the studies by Tseng et $\mathrm{al}^{1}$ and Bae et $\mathrm{al}^{2}$ it was observed that MC differs from IDCNOS in having early stage, high hormonal receptor expression (ER and PR), less HER 2 Neu amplifications, lower rate of lymphovascular, and lymph node involvement. Bae et $\mathrm{al}^{2}$ also documented that PMCs have better disease-free survival and overall survival compared with IDC-NOS. Fujii et al ${ }^{12}$ and Lacroix-Triki et al ${ }^{13}$ found less number of genetic abnormalities among PMC than other types of breast carcinomas indicating PMCs are molecularly different from other types.

MCs are usually confined to lower stage, same has also been observed in the present study (stage I $=2$, stage II $=8$, and stage III $=3$ ). MCs are known for high hormone receptor expression (ER and PR) and less HER 2 Neu expression; same has also been observed in the present study and no difference was noted among PMC and MMC as recorded in the literature. ${ }^{14}$ However, MMC cases expressed high proliferative marker ( $\left.\mathrm{K}_{\mathrm{i}}-67\right)$; this can be due to more solid components of MC. Lei et $\mathrm{al}^{4}$ observed increased p53 expression among MMC. MC expressed androgen receptor more than IDC-NOS. ${ }^{1}$

There is a debate on the prognostic factors associated with MC but there is a universal agreement among the authors that lymph node status is the key prognostic factor. ${ }^{1-4}$ In the present study, PMC cases had more favorable survival than MMC. Disease-associated complications were more in MMC than PMC (five vs. one, $p=0.03$ ). All the six cases had lymph node metastasis at the time of diagnosis. It has also been observed in the present study that age, tumor size, and hormonal receptor status were not contributing to lymph node metastasis. In a study by Avisar et $a l,{ }^{15}$ observed young age, aneuploidy, nuclear grade, and negative ER receptor are associated with lymph node metastasis. Di Saverio et a ${ }^{16}$ observed that tumor size is an independent prognostic factor but less than age and nodal status. Toikkanen and Kujari ${ }^{17}$ observed that MCs with aneuploid had advanced stage tumor and nodal status.

The presence of mucin is a favorable prognostic factor. It forms a container for the tumor cells and decreases the mobility of tumor cells leading to less metastasis. It has also been documented that MCs with high expression of MUC2 are having less lymphovascular invasion and lymph node metastasis. ${ }^{18}$ Bae et $\mathrm{al}^{2}$ observed that nodal status and adjuvant therapy are better prognostic markers.

The primary modality of treatment is surgery followed by adjuvant treatment. ${ }^{3}$ Adjuvant hormonal therapy is indicated if hormonal receptors are positive. The benefit of the chemotherapy needs to be carefully established before starting it and it is indicated in MC if the tumor size is more than $3 \mathrm{~cm}$ and if lymph nodes are positive. ${ }^{1}$

It is evident from the observation of our study and also from the review of literature that PMCs are rare subtypes of breast cancers. The diagnostic cytological features are ECM, MVF, and SRC. They are clinicopathologically and genetically distinct from their fellow MMCs and other subtypes of breast cancers. Lymph node involvement is the key prognostic factor and it is independent of age, size of tumor, adjuvant therapy, and hormonal receptor expression. They have better long-term prognosis.

\section{Conflict of Interest}

None declared.

\section{References}

1 Tseng HS, Lin C, Chan SE, et al. Pure mucinous carcinoma of the breast: clinicopathologic characteristics and long-term outcome among Taiwanese women. World J Surg Oncol 2013;11:139

2 Bae SY, Choi MY, Cho DH, Lee JE, Nam SJ, Yang JH. Mucinous carcinoma of the breast in comparison with invasive ductal carcinoma: clinicopathologic characteristics and prognosis. J Breast Cancer 2011;14(4):308-313

3 Dumitru A, Procop A, Iliesiu A, et al. Mucinous breast cancer: a review study of 5 year experience from a hospital-based series of cases. Maedica (Buchar) 2015;10(1):14-18

4 Lei L, Yu X, Chen B, Chen Z, Wang X. Clinicopathological characteristics of mucinous breast cancer: a retrospective analysis of a 10-year study. PLoS One 2016;11(5):e0155132

5 Tyagi R, Kumar M, Tanwar P, Dey P. Mucinous carcinoma of breast: FNAC as effective diagnostic modality. Asian J Med Sci 2012;11:32-35

6 Jayaram G, Swain M, Chew MT, Yip CH, Moosa F. Cytology of mucinous carcinoma of breast: a report of 28 cases with histological correlation. Malays J Pathol 2000;22(2):65-71

7 Adhikari RC, Jha A, Sayami G. Fine needle aspiration cytology findings of mucinous carcinoma of breast: a study of eight cases with histological correlation. J Pathol Nepal 2012;2:285-288

8 Ingle AP, Kulkarni AS, Patil SP, Kumbhakarna NR, Bindu RS. Mucinous carcinoma of the male breast with axillary lymph node metastasis: report of a case based on fine needle aspiration cytology. J Cytol 2012;29(1):72-74

9 Sharma S, Bansal R, Khare A, Agrawal N. Mucinous carcinoma of breast: cytodiagnosis of a case. J Cytol 2011;28(1):42-44

10 Nayak SK, Naik R, Upadhyaya K, Raghuveer CV, Pai MR. FNAC diagnosis of mucinous carcinoma of male breast-a case report. Indian J Pathol Microbiol 2001;44(3):355-357

11 Haji BE, Das DK, Al-Ayadhy B, et al. Fine-needle aspiration cytologic features of four special types of breast cancers: mucinous, medullary, apocrine, and papillary. Diagn Cytopathol 2007;35(7):408-416

12 Fujii H, Anbazhagan R, Bornman DM, Garrett ES, Perlman E, Gabrielson E. Mucinous cancers have fewer genomic alterations than more common classes of breast cancer. Breast Cancer Res Treat 2002;76(3):255-260

13 Lacroix-Triki M, Suarez PH, MacKay A, et al. Mucinous carcinoma of the breast is genomically distinct from invasive ductal carcinomas of no special type. J Pathol 2010;222(3):282-298

14 Cao AY, He M, Liu ZB, et al. Outcome of pure mucinous breast carcinoma compared to infiltrating ductal carcinoma: a population-based study from China. Ann Surg Oncol 2012;19(9):3019-3027

15 Avisar E, Khan MA, Axelrod D, Oza K. Pure mucinous carcinoma of the breast: a clinicopathologic correlation study. Ann Surg Oncol 1998;5(5):447-451

16 Di Saverio S, Gutierrez J, Avisar E. A retrospective review with long term follow up of 11,400 cases of pure mucinous breast carcinoma. Breast Cancer Res Treat 2008;111(3):541-547

17 Toikkanen S, Kujari H. Pure and mixed mucinous carcinomas of the breast: a clinicopathologic analysis of 61 cases with long-term follow-up. Hum Pathol 1989;20(8):758-764

18 García-Labastida L, Garza-Guajardo R, Barboza-Quintana O, et al. CDX-2, MUC-2 and B-catenin as intestinal markers in pure mucinous carcinoma of the breast. Biol Res 2014;47:43 